\title{
2020: Clutching the Endless Loop
}

\author{
Zafar Ullah Chaudhry
}

Dear Readers,

The year 2020, definitely, was the mostmomentous year in the history. A year when everyone became wise, sharing their wise ancestral medical recipes with the world, both orally and in writing because of the contagion that enveloped the whole planet. The entire world was devastated by the same infection, changing the literal meaning of devastation. Hence, the health related issues were quite exceptional due to novel Covid-19 strain of corona virus. Researchers, social media, politicians, professionals from all fields focused the same subject.

At the time when Covid-19 was tearing the world apart, the writers were gearing up to grab the most wanted time provided by corona-induced lockdown. Generally, worldwide it was so quiet that one can hear his thinking, just the right kind of ambiance you need forcreative writing.

The offices of JCPSP were also closed for three months. Similarly, this was a blessing in disguise to everyone in periodical profession. The online system, that we have been struggling with, gained perfection. Consequently, the work from home concept expanded to near perfection; and individuals like us, who considered it close to impossible, were pleased to realise it is simply within our capabilities. Thus, JCPSP had a remarkable progress with $41.7 \%$ increase in number of submissions, from 1,618 in 2019 to 2,292 in 2020. Although, these comprised all categories, but the Covid-19 submissions surpassed all others, 322 submissions in the last 7 months; since, currently medical research is dominated by coronavirus. Like all journals worldwide, at JCPSP, we also gave priority to Covid-19 manuscripts, expediting the review process, to keep the world abreast of this unpredictable virus. As such, 65 Covid-19 submissions have been successfully published.

The highest international contributor of 2020 was again Turkey with 735 (32\%) submissions. China, as always, is our another exceptional contributor with 316 (13\%) submissions. The contributions from Pakistan also increased from 769 last year to 973 in 2020, a 26\% increase in submissions, proving that there is silver lining to every catastrophe. The rest of 268 submissions were from 32 different countries, almost all around the world. This year rejection and withdrawal rate was remarkably higher, $1,768(77 \%)$ - related to a number of reasons, manuscript quality, high similarity, lack of original or valuable knowledge.

Though, JCPSP electronic management strategy is working efficiently channelling communication with authors, editors and reviewers through OAS, but demands imposed by lockdown were enormous. The work from home strategy was successfully accomplished from the day one. At JCPSP, our editors, team members, IT experts etc. are ready to face any challenges enforced by situations created by ecological or pathological insults.

I wish all of our contributors a happy new year and eager to receive any suggestion for further improvement.

Correspondence to: Prof. Zafar Ullah Chaudhry, President CPSP and Chief Editor JCPSP, Department of Publications, College of Physicians and Surgeons Pakistan, 7th Central Street, Phase II, DHA, Karachi, Pakistan

E-mail:publications@cpsp.edu.pk 